\title{
Development of Bioclimatic Design Tool for Oman Using Dry Bulb and Dew Point Temperatures Open Database
}

\author{
N.A. Al-Azri ${ }^{*}$, a, Y. Zurigat ${ }^{\mathrm{b}}$ and N. Al-Rawahia \\ $*^{a}$ Department of Mechanical and Industrial Engineering, College of Engineering Sultan Qaboos University, Muscat, Oman. \\ ${ }^{b}$ Department of Mechanical Engineering, American University of Sharjah, Sharjah, UAE.
}

Received 14 March 2017; Accepted 28 September 2017

\begin{abstract}
Bioclimatic charts are used by engineers and architects in implementing passive cooling systems and architectural optimization with respect to natural air conditioning. Conventionally, the development of these charts is based on the availability of typical meteorological year which requires a record of meteorological data that are rarely available in sufficient amounts. Bioclimatic charts in Oman were developed earlier by the authors for limited locations based on the available typical meteorological years. Using dry bulb and dew point temperatures only, bioclimatic charts are developed for Adam, Buraimi, Ibra, Muscat, Nizwa, Rustaq, Saiq, Salalah, Suhar and Sur. These charts are better representative of bioclimatic trends since their development is mainly based on the relevant parameters, namely dry bulb temperature and dew point.
\end{abstract}

Keywords: Bioclimatic charts; Passive cooling; TMY.

$$
\begin{aligned}
& \text { تطوير تصميم أداة المناخ الحيوي لعمان باستخدام قاعدة بيانات درجات حرارة المصباح الجاف } \\
& \text { و قّطر الندى } \\
& \text { ناصر العزري؛‘*، يوسف زريقات و نبيل الرواحي' }
\end{aligned}
$$

*Corresponding author's e-mail: nalazri@squ.edu.om 


\section{Introduction}

Bioclimatic charts are tools used at the design phase in building architecture. These charts help engineers and architects decide suitable passive air conditioning tools and also indicate the effectiveness of each tool. The development of bioclimatic charts usually requires the typical meteorological data at a given location. For the development of typical meteorological years (TMYs), a full record of weather data including dry bulb temperature, dew point, wind speed and solar radiation must be available. Typical metrological years (TMYs) are usually intended for a wide spectrum of applications including energy simulation, renewable energy applications, agricultural and architectural applications. For such versatility of uses, all of the above meteorological parameters are required. However, a full record of all data is rarely available and if it is, the likelihood of having missing gaps, unrealistic measurements and inaccuracies is very high.

In the development of typical metrological years, a historical record of hourly readings of the meteorological parameters is analyzed statistically. The historical record extends to up to 12 years with each parameter analyzed separately using Frankenstein-statistics. For each of the 12 months in the year, a representative month is selected from the record based on a weighed sum of the different parameters. Parameters that have greater impact will take a higher weight. Since solar radiation impacts all other meteorological parameters, it is always assigned the highest weight in the development of a general-purpose typical metrological year. This statistical method was first devised by Sandia National Laboratories (NSRDB 1992) for US locations with historical records between 1961 and 1990. Two other versions of Sandia method, namely TMY2 and TMY3, came later and they were different in the weights assigned to each parameter. The same method was used in different works in the literature but by introducing or excluding some of the parameters and redistributing the assigned weights (Al-Azri 2016).

Al-Azri (2016) used a tailored typical meteorological year for the development of bioclimatic charts which only considers the relevant bioclimatic parameters; namely, dry bulb temperature and dew point. In the development of the tailored typical meteorological year by Al-Azri (2016), the method developed by Sandia National Laboratories (Hall et al. 1978, NSRDB 1992) was used; however, both solar radiation and wind speed were assigned zero weight. The other relevant parameters were assigned the weights shown in Table 1.

Currently, bioclimatic charts for Oman are only developed for eight locations where TMYs already exist (Al-Azri et al. 2013). These locations are: Buraimi, Majis, Seeb, Sur, Fahud, Masirah, Marmul and Salalah using the typical meteorological year developed by Sawaqed et al. (2005) based on the then available records of meteorological data, mainly between 1995 and 2004. In the presented work, dry bulb temperature and dew point are used to develop bioclimatic charts for Adam, Buraimi, Ibra, Muscat, Nizwa, Rustaq, Saiq, Salalah, Suhar and Sur. These locations, shown in Fig. 1, feature diverse weather behavior. The northern costal locations are intensively affected by high humidity. The interior locations are usually hot and dry except Saiq. Two locations maintain special cases which are Saiq due to its high elevation (1,755 $\mathrm{m}$ above sea level) and Salalah which is affected by the monsoon.

Table 1. The weights used in the development of the typical meteorological year by Al-Azri (2016).

\begin{tabular}{lcc}
\hline Parameter & Dry bulb & Dew point \\
\hline Maximum daily & $1 / 10$ & $1 / 10$ \\
Minimum daily & $1 / 10$ & $1 / 10$ \\
Mean daily value & $2 / 10$ & $2 / 10$ \\
Daily range & $1 / 10$ & $1 / 10$ \\
\hline
\end{tabular}

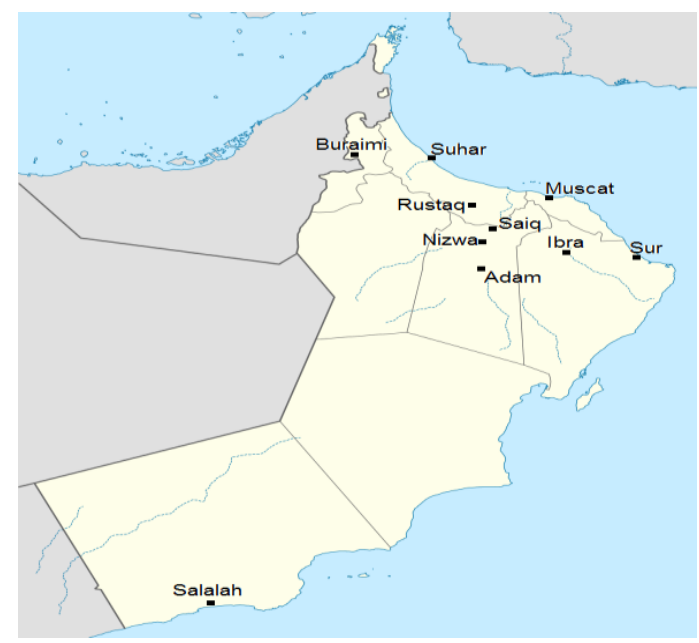

Figure 1. Map of Oman with the ten studied locations. 


\section{Bioclimatic Charts}

The bioclimatic chart model used in this work is developed by Givoni (1992, 1994). It features five zones projected on a psychrometric chart with each zone representing a passive cooling technique. The typical meterological year for each location was developed. The average of the daily maximum and minimum dry bulb temperature and absolute humidity are calculated for each month. For each month, the average of the daily maximum temperature is matched with the average of the minimum daily absolute humidity represented by the pair $\left(\bar{T}_{\text {Max }}, \bar{w}_{\text {Min }}\right)$. Likewise, the average of the daily minimum temperature is matched with the average daily minimum absolute humidity to form $\left(\bar{T}_{\text {Min }}, \bar{w}_{\text {Max }}\right)$. The two points are connected to form a line segment representing the distribution of the points in that month.

Several variants of bioclimatic charts can be found in the literature. All charts are overlaid on psychrometric charts and hence the same parameters, dry bulb temperature and absolute humidity, are used. With the knowledge of the average atmospheric pressure, absolute humidity can be calculated as a function of the dew point and the dry bulb temperature. Relative humidity was calculated as a function of dry bulb temperature, dew point and atmospheric preassure; the complete calculations associated with the chart development can be found in (Al-Azri et al. 2013).

\section{Methodology}

Due to the scarcity of solar radiation data, development of a typical meteorological year based on the conventional Sandia method or any of its variants is not possible. Typical meteorological years based on dry bulb temperature and dew point is followed as described by Al-Azri (2016). The method is advantageous in that it requires records of dry bulb and dew point temperatures only which are more commonly available than other meterological parameters. Moreover, restricting the development of this typical year to the relevent parameters should be more accurate. Having irrelevant parameters such as solar radiation, which is assigned greater weight in the conventional TMY development, can drive the typical values to lean towards the trend of the irrelevant parameters and hence compromise the accuracy of the representation of the more relevant parameters in the developed typical year.

Figure 2 shows the bioclimatic chart of Muscat using the third generation Sandia Method (TMY3) along with the one based on the relevant parameters: dry bulb temperature and dew point. The comparison features identical distribution of the line segments on the bioclimatic charts but with little misalignment between the two approaches. The misalignment is due to the exclusion of the irrelevant parameters.

\section{Results}

Records of hourly weather data were collected for ten locations for 12 years (2005-2016). The ten locations are Adam, Buraimi, Ibra, Muscat, Nizwa, Rustaq, Saiq, Salalah, Suhar and Sur. The data was acquired from the National Climatic Data Center (NCDC) of the American National Oceanic and Atmospheric Administration (NOAA). Information on the ten locations is given in Table 2 .

For each of the locations, the typical meteorological years for dry bulb temperature and dew point were developed using records of hourly readings of the 12 years; from 2005 to 2016. The acquired data has many missing points. Nevertheless, they do not have a continuous period of missing data and hence missing data were properly treated by interpolation. Short hourly gaps were treated using linear interpolation while extended gaps were interpolated for using readings of the same hours in the adjacent days.

Figures 3 to 12 show the developed bioclimatic charts for Adam, Buraimi, Ibra, Muscat, Nizwa, Rustaq, Saiq, Salalah, Suhar and Sur, respectively. The ten charts represent different behaviour depending on the location.

For most locations, natural thermal comfort mainly takes place in the months from November to February. The months from June to September are typically hot months where mechanical air conditioning is necessary. 


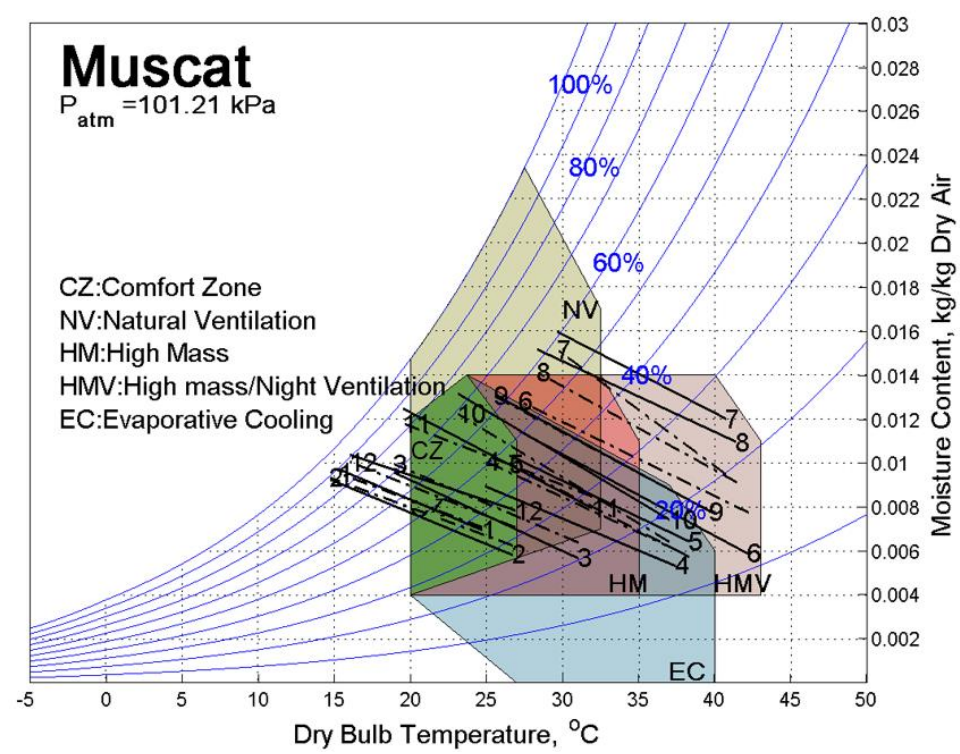

Figure 2. Givoni bioclimatic chart for Muscat, Oman using Sandia third version of meterological typical years (TMY3) approach (solid lines) and the approach based on the dry bulb and dew point temperatures (dashed lines) (Al-Azri 2016).

Table 2. The ten locations for which bioclimatic charts are developed.

\begin{tabular}{lcccc}
\hline Location & Station ID & Latitude & Longitude & Elevation $(\mathbf{m})$ \\
\hline Adam & 412640 & 22.5 & 57.367 & 328 \\
Buraimi & 412440 & 24.233 & 55.783 & 299 \\
Ibra & 412650 & 22.733 & 58.5 & 469 \\
Muscat & 412560 & 23.593 & 58.284 & 14.6 \\
Nizwa & 412550 & 22.867 & 57.55 & 462 \\
Rustaq & 412530 & 23.417 & 57.433 & 322 \\
Saiq & 412540 & 23.067 & 57.633 & 1,755 \\
Salalah & 413160 & 17.039 & 54.091 & 22.3 \\
Suhar & 412460 & 24.467 & 56.633 & 4.0 \\
Sur & 412680 & 22.533 & 59.483 & 14.0 \\
\hline
\end{tabular}

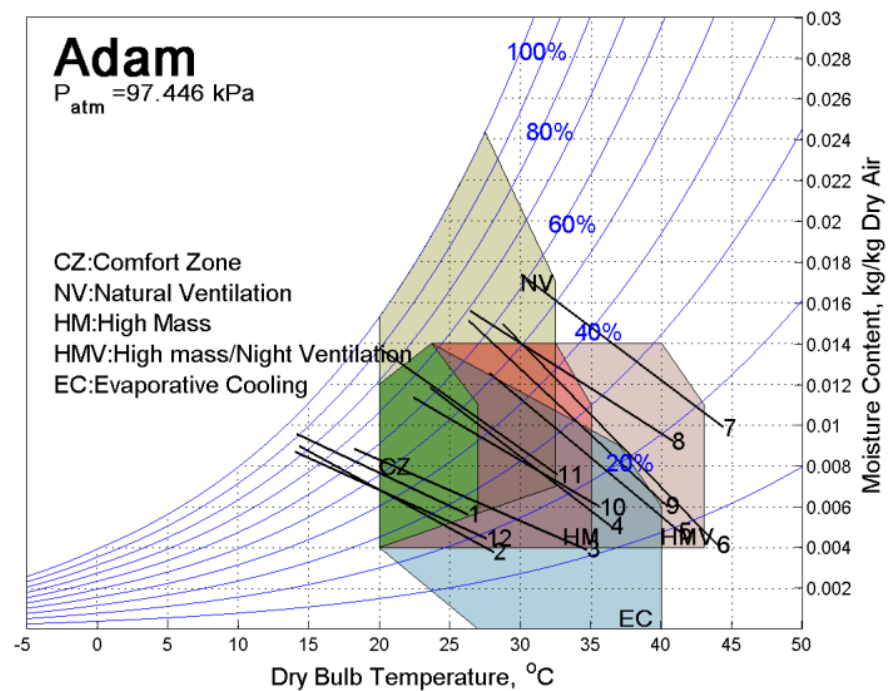

Figure 3. Bioclimatic chart for Adam. 


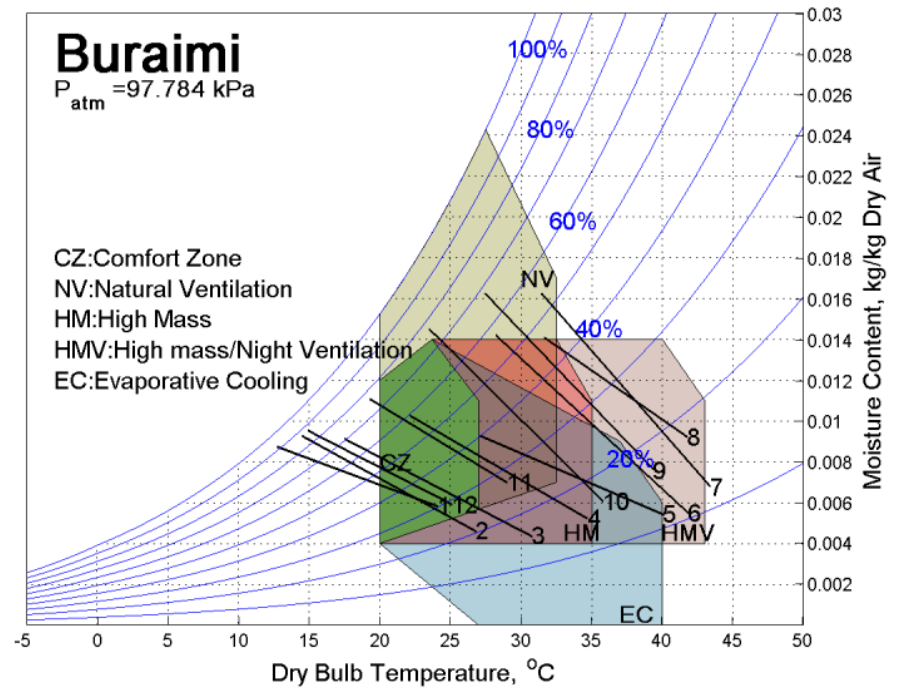

Figure 4. Bioclimatic chart for Buraimi.

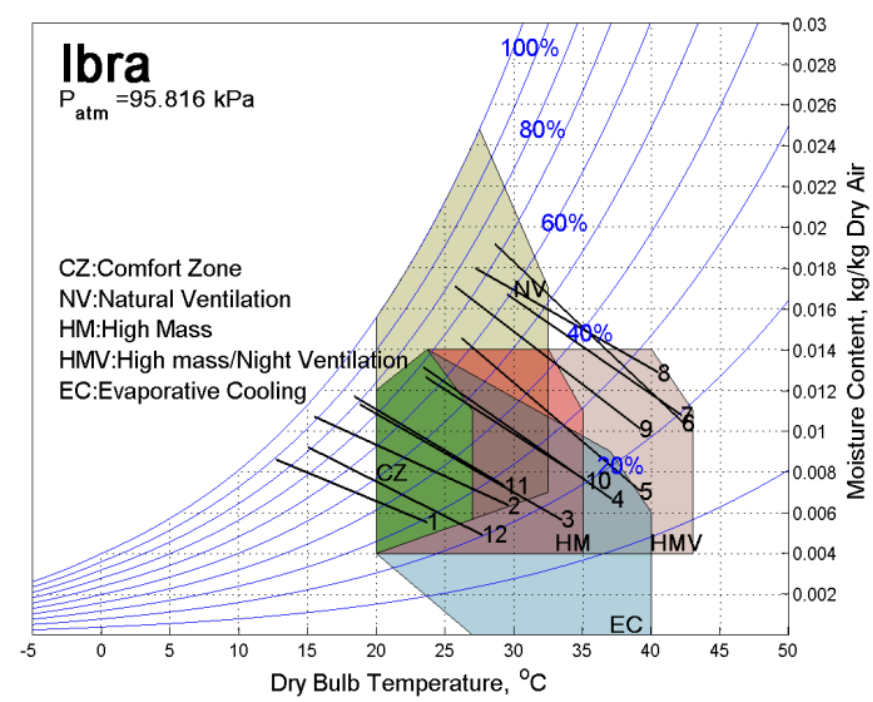

Figure 5. Bioclimatic chart for Ibra.

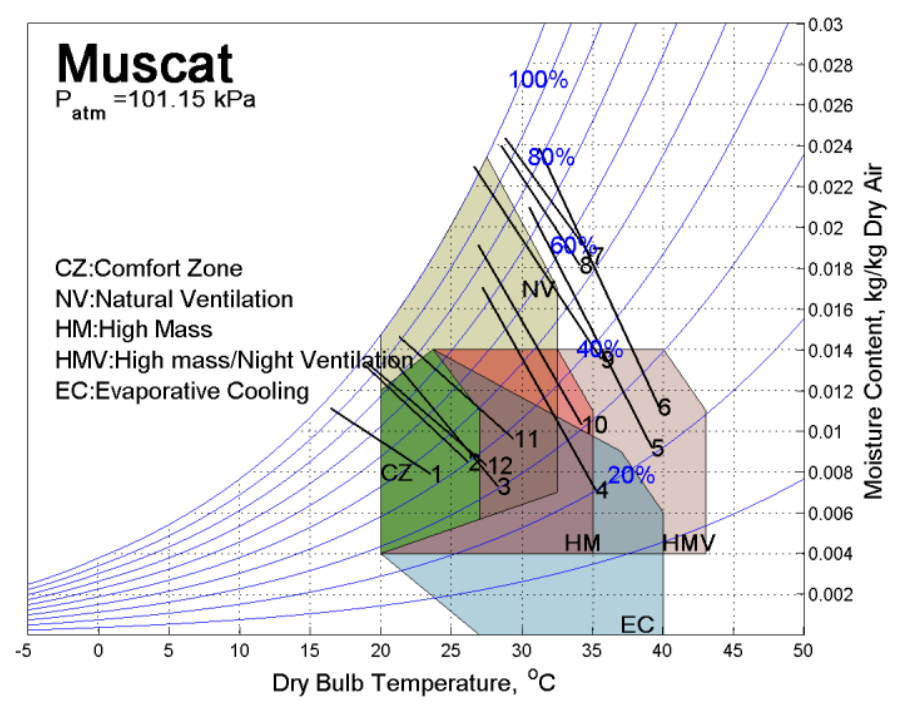

Figure 6. Bioclimatic chart for Muscat. 


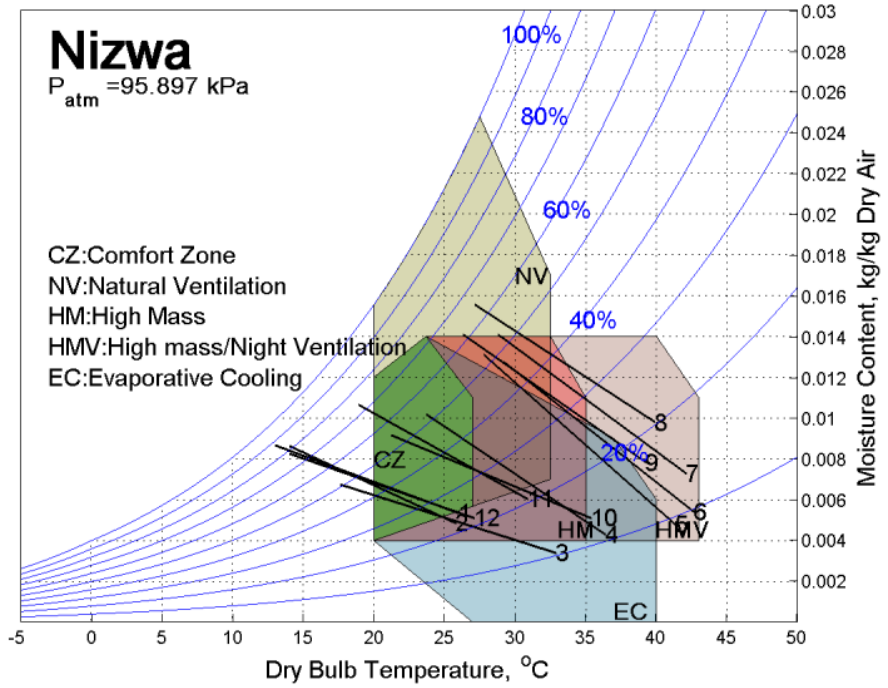

Figure 7. Bioclimatic chart for Nizwa.

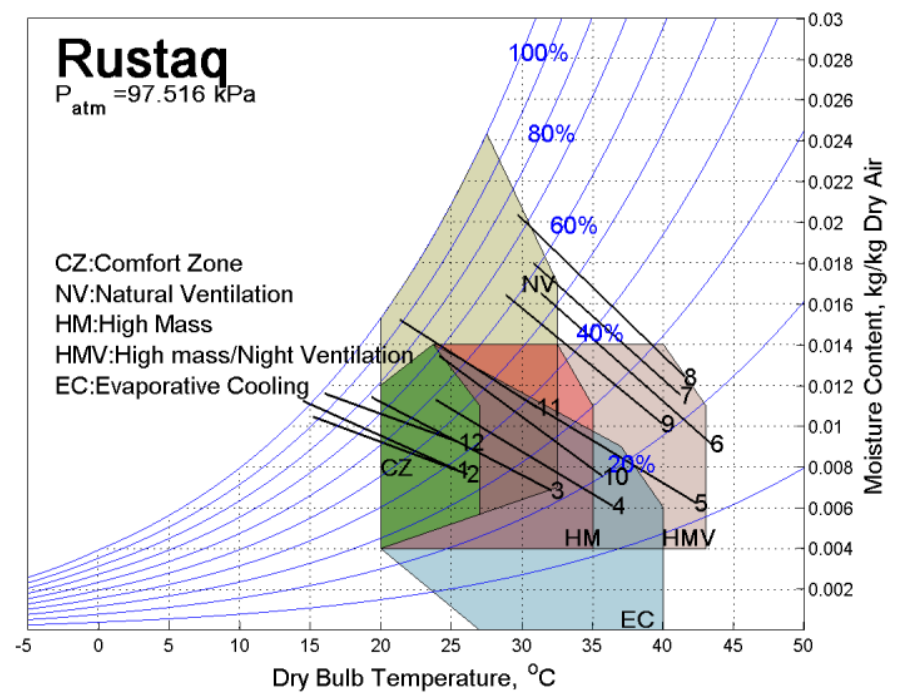

Figure 8. Bioclimatic chart for Rustaq.

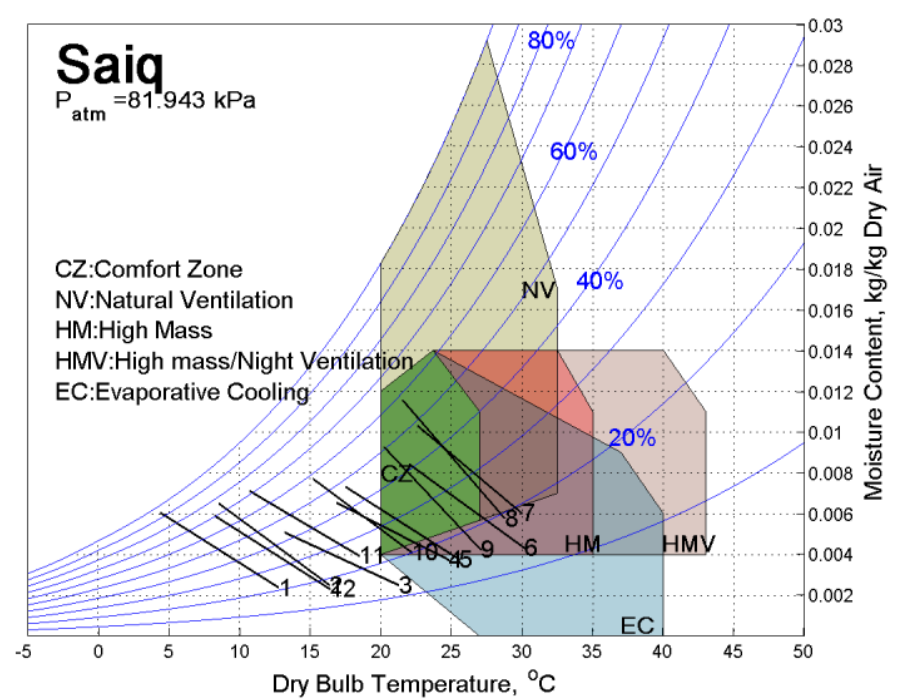

Figure 9. Bioclimatic chart for Saiq. 


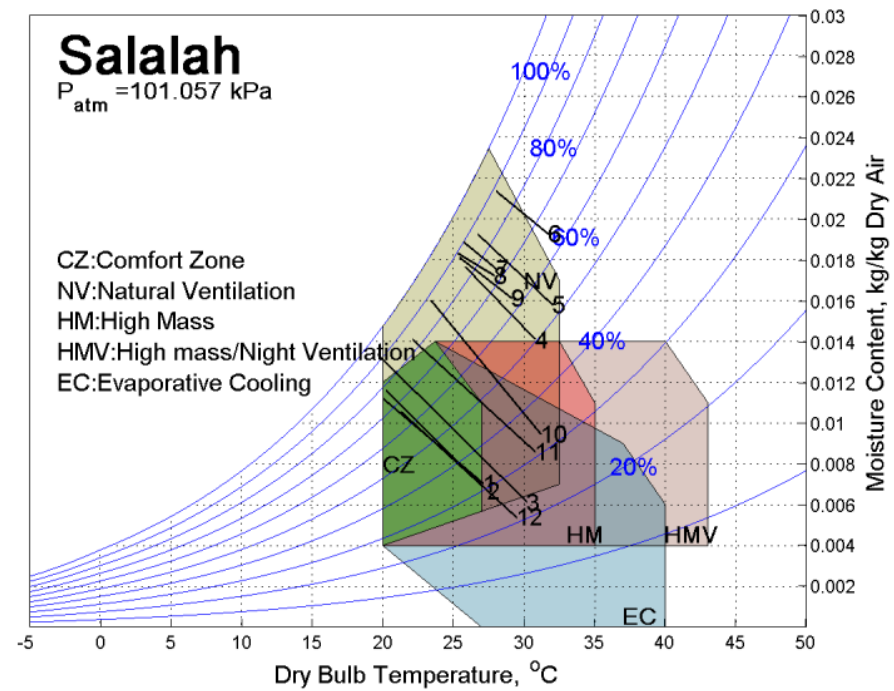

Figure 10. Bioclimatic chart for Salalah.

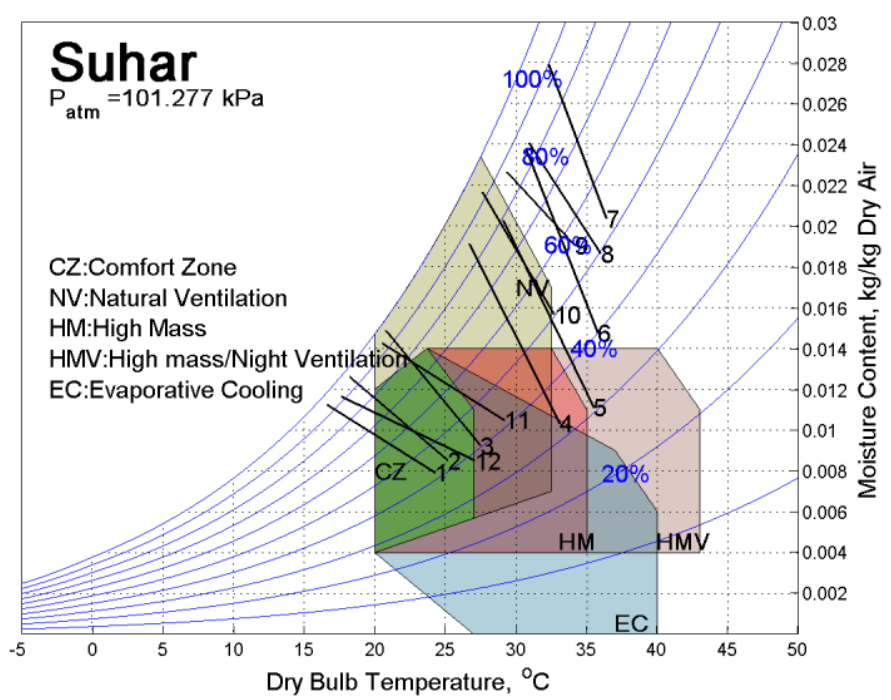

Figure 11. Bioclimatic chart for Suhar.

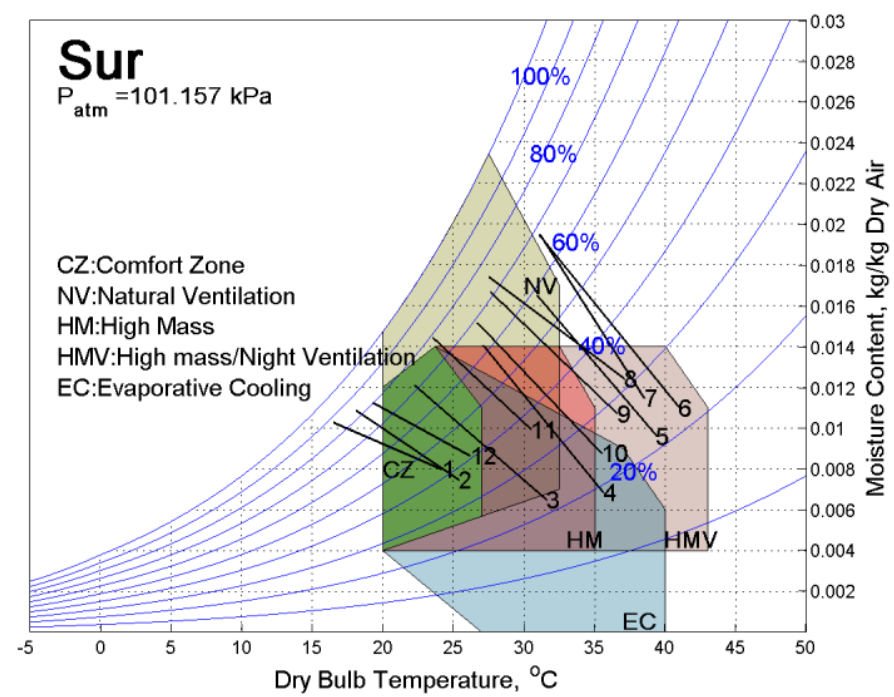

Figure 12. Bioclimatic chart for Sur. 
The ten locations can be divided into four groups:

- Interiors at normal elevation: Adam, Buraimi, Ibra, Nizwa and Rustaq

- Interiors at high elevation: Saiq

- North coastal: Muscat, Suhar and Sur

- South coastal: Salalah

The interior locations at normal elevation are dry and hot. Natural comfort is mainly maintened from part of November to February. The only interior location at high altitude which is saiq, has a very dry climate with thermal comfort restored from April to October while heating is necessary from November to March. The north coastal locations are apperantly very humid with natural comfort attained mostly from December to February. Salalah in the south presents a special case due to the impact of the monsson and so dry bulb temperature is relatively lower than those of northern coastal regions.

\section{Conclusion}

Due to the lack of complete record of weather and solar radiation data, developing bioclimatic charts based on dry bulb temperature and dew point is very useful to the majority of locations in Oman. Bioclimatic charts were developed for ten locations and they showed consistent trends with their geographical features.

\section{Conflict of Interest}

The authors declare no conflicts of interest.

\section{Funding}

No funding was received for this research.

\section{References}

Al-Azri NA (2016), Development of a typical meteorological year based on temperature and humidity for passive cooling applications. Energy for Sustainable Development 33: 61-74.

Al-Azri N, Zurigat Y, Al-Rawahi N (2013), Development of bioclimatic chart for passive building design. International Journal of Sustainable Energy 32(6): 713-723.
Givoni B (1992), Comfort, climate analysis and building design guidelines. Energy and Buildings 1: 11-23.

Givoni B (1994), Passive and Low Energy Cooling of Buildings. Van Nostrand Reinhold, New York.

Hall I, Prairie R, Anderson H, Bose E (1978), Generation of typical meteorological years for 26 SOLMET stations. SAND78-1601. Albuquerque, NM, Sandia National Laboratories.

NSRDB (1992), User's Manual - National Solar Radiation Data Base (1961-1990). Version 1.0. Golden, CO: National Renewable Energy Laboratory and Asheville, NC: National Climatic Data Center.

Sawaqed NM, Zurigat YH, Al-Hinai HA (2005), Step-by-Step application of sandia method in developing typical meteorological years for different locations. International Journal of Energy Research 29(8): 723-737. 